\title{
Flow characterization of magnesium alloy ZK61 during hot deformation with improved constitutive equations and using activation energy maps
}

\author{
Jinchuan Long ${ }^{a, b}$, Qinxiang Xia ${ }^{a, *}$, Gangfeng Xiao ${ }^{a}$, Yi Qin ${ }^{\text {b, }}$, Shuai Yuan ${ }^{a}$ \\ (a. School of Mechanical and Automotive Engineering, South China University of Technology, \\ Guangzhou 510640, China; b. Centre for Precision Manufacturing, DMEM, The University of \\ Strathclyde, Glasgow G1 1XQ, UK)
}

\begin{abstract}
The present study aimed at characterizing the flow characteristics and workability of an as-extruded magnesium alloy ZK61 by isothermal compression tests performed at temperatures of $523-673 \mathrm{~K}$ and strain rates of $0.001-1 \mathrm{~s}^{-1}$. The flow stress curves were analyzed via considering the mechanism of microstructure evolution. Using the obtained flow stress data, both of the conventional and improved Arrhenius constitutive equations were developed to predict the flow characteristics, and the 3D activation energy maps were constructed to propose the optimal deformation conditions and reveal the effects of deformation parameters on microstructure evolution. It can be found that the strain factor plays an important role in determining the shapes of the flow stress curves, which exhibit three types of variation tendencies due to the flow softening and hardening behaviour as the strain increases. The improved constitutive equations resulted in excellent predictability of the peak flow stress within all the deformation conditions. Combining with the activation energy maps, the dominant deformation mechanisms, i.e., dynamic recrystallization and flow localization in different deformation regions were identified, and the optimal processing window of the alloy can be obtained at strain rate and temperature range of $0.001-0.01 \mathrm{~s}^{-1}$ and $623 \sim 673 \mathrm{~K}$ under a certain strain of 0.9 .
\end{abstract}

Keywords: Magnesium alloys; Hot deformation; Flow characteristics; Workability; Constitutive equations; Aactivation energy map 


\begin{tabular}{|ll|ll|}
\hline Nomenclature & & $\sigma_{\mathrm{s}}$ & yield stress, $(\mathrm{MPa})$ \\
$\sigma$ & flow stress, $(\mathrm{MPa})$ & $E_{\mathrm{i}}$ & experimental flow stress, $(\mathrm{MPa})$ \\
$K$ & material constant & $P_{\mathrm{i}}$ & predicted flow stress, $(\mathrm{MPa})$ \\
$\dot{\varepsilon}$ & strain rate, $\left(\mathrm{s}^{-1}\right)$ & $\bar{E}$ & experimental mean flow stress, $(\mathrm{MPa})$ \\
$m$ & strain rate sensitivity index & $\bar{P}$ & predicted mean flow stress, $(\mathrm{MPa})$ \\
$T$ & deformation temperature, $(\mathrm{T})$ & $N$ & number of data points \\
$\alpha$ & stress multiplier & $\rho$ & density of mobile dislocations, $\left(\mathrm{m}^{-2}\right)$ \\
$R$ & ideal gas constant, $(\mathrm{J} / \mathrm{mol} \cdot \mathrm{K})$ & $b$ & Burgers vector, $(\mathrm{nm})$ \\
$Q_{\mathrm{act}}$ & activation energy, $(\mathrm{J} / \mathrm{mol})$ & $\bar{v}$ & mean speed of dislocation motion, $(\mathrm{m} / \mathrm{s})$ \\
$A, A_{1}, A_{2}$, & material parameters & $v$ & attempt frequency, $\left(\mathrm{s}^{-1}\right)$ \\
$n, n_{1}, \beta$ & & $k$ & Boltzmann constant, $(\mathrm{J} / \mathrm{K})$ \\
$\sigma_{\mathrm{p}}$ & peak stress, $(\mathrm{MPa})$ & $\Delta \mathrm{G}\left(\sigma_{\mathrm{s}}\right)$ & free energy of activation, $(\mathrm{J} / \mathrm{mol})$ \\
$\theta$ & strain hardening rate & $\Delta \mathrm{F}$ & total free energy, $(\mathrm{J} / \mathrm{mol})$ \\
$\mathrm{Z}$ & Zener-Hollomon parameter, $\left(\mathrm{s}^{-1}\right)$ & $\tau$ & external stress, $(\mathrm{MPa})$ \\
\hline
\end{tabular}

\section{Introduction}

Owing to their low density, high strength-to-weight ratio, magnesium $(\mathrm{Mg})$ and its alloys are of great interest for lightweight applications in sectors that include the aeronautics/aerospace and automotive industries [1]. However, the limited ductility of $\mathrm{Mg}$ alloys at room temperature results from the contrasting critical resolved shear stresses (CRSS) among the basal, prismatic, pyramidal slip systems [2]. This becomes a major obstacle for large-scale commercial applications of $\mathrm{Mg}$ alloys with hexagonal close-packed crystal structures [3]. The dominant deformation modes in $\mathrm{Mg}$ alloys contain basal $<\mathrm{a}>$ slip, prismatic $<\mathrm{a}>$ slip, pyramidal $<\mathrm{c}+\mathrm{a}>$ slip and mechanical twinning [4, 5]. The basal <a> slip with the lowest CRSS is readily activated but has just two independent slip systems, these are inadequate to fulfill the von Mises criterion. Although the non-basal slips can offer more independent slip systems and coordinate the deformation along the c-axis, these are difficult to activate because of high CRSS at room temperature. However, the CRSS decreases rapidly as temperature increases [6]. Hence, $\mathrm{Mg}$ alloys are generally subjected to hot deformations

\footnotetext{
* Corresponding author.

E-mail addresses: meqxxia@scut.edu.cn (Q.X.Xia), qin.yi@strath.ac.uk (Y. Qin)
} 
(such as rolling, forging, extrusion and spinning) in processing [7]. Because of its influence on the microstructure refinement, hot deformation is also considered as an effective way of enhancing the properties of Mg-based products [8].

Since the strain hardening and softening behaviours of materials are remarkably influenced by deformation parameters, their flow behaviour during hot deformation is complicated and exhibits obvious differences due to the distinct chemical compositions [9]. These affect the necessary deformation energy and kinetics of the metallurgical phenomena [10], including the work hardening (WH), dynamic recovery (DRV) and dynamic recrystallization (DRX) [11]. Therefore a detailed knowledge on how $\mathrm{Mg}$ alloys behave under hot deformation conditions is a prerequisite for industrial production. An accurate description of flow behaviour is fundamentally important for developing a proper metal-forming process route. This is also significant for performing the Finite Element (FE) analysis to obtain the optimal deformation parameters.

The flow behaviour which can be invariably described by the constitutive equations, is essential for the reliability of FE simulation results [12]. There are three typical constitutive equations for characterizing the flow behaviour of metallic materials: phenomenological equations, physical-based equations and artificial neural network (ANN) equations [13]. Among these available equations, the

phenomenological equations with few material constants are convenient and only a small number of experimental data are needed, especially the Arrhenius constitutive equation. As well as considering the micro-mechanisms like dislocation dynamics, lots of material constants are required in the physical-based equations resulting in complex calculations. The accuracy of the prediction by the ANN equations may be higher than that of other constitutive equations, but it normally has high requirement for the availability of extensive, high-quality data and characteristic variables [14].

To date, a series of effort have been made to characterize the hot flow behaviour of $\mathrm{Mg}$ alloys in terms of developing constitutive equations. Due to its accessibility and a wide range of adaptability, the Arrhenius equation is still the most widely used equation, such as that used in the study of cast and homogenized AZ91 [15, 16], extruded AE21 [17], hot-rolled and homogenized AZ31 [18, 19], T5-Treated ZK61 [20], extruded and T4-Treated ZK60 [21, 22], Mg-Zn-Y-Zr alloy [23], a cast Mg (Mg-Al-Ca) alloy [24]. However, when it comes to the determination of the peak stress, the material parameters of constitutive equations in most of the aforementioned studies were 
treated as constants which are independent from the deformation conditions. The shortcomings can lead to an unrealistic prediction of the flow behaviour during hot deformation.

As the most important characteristic for hot working, the activation energy ( $\left.Q_{\text {act }}\right)$ reflecting the workability of material, can be closely connected with thermodynamic mechanism of dislocation motion [25]. The value of $Q_{\text {act }}$ influenced by deformation parameters is difficult to remain constant within a working range, but it can provide additional information on the underlying deformation mechanism related to the microstructural evolution. Also, improved workability can be achieved under deformation conditions with a low $Q_{\text {act }}[26]$. It is therefore crucial to understand the influence of deformation parameters and microstructural evolution on dislocation motion in order to establish a description of an internal relation between the $Q_{\text {act }}$ and workability of the materials.

The activation energy for hot deformation of Mg alloys has been studied intensively in recent years. For instance, Mei et al. [15] studied the hot deformation of a homogenized AZ91 alloy, and they found that the $Q_{\text {act }}$ decreases linearly with increase of the strain. Su et al. [27] studied the hot deformation of an extruded AZ80 alloy, and the $Q_{\text {act }}$ was estimated as $142 \mathrm{~kJ} / \mathrm{mol}$ under various temperatures and strain rates. Schindler et al. [28] studied the evolution of the $Q_{\text {act }}$ of rolled AZ31 alloy during hot compression, and found that the $Q_{\text {act }}$ is equal to $158 \mathrm{~kJ} / \mathrm{mol}$ for flow curves with conventional shape, while the $Q_{\text {act }}$ is $146 \mathrm{~kJ} / \mathrm{mol}$ for the flow curves at the concave initial stage. Arun and Chakkingal analyzed the hot deformation of the annealed and ECAPed AZ31B alloy, and they found that the $Q_{\text {act }}$ in the annealed condition $(161.6 \mathrm{~kJ} / \mathrm{mol})$ decreases after ECAP due to the grain refinement [29]. However, the combined influences of deformation parameters (including temperature, strain rate and strain) on the evolution of $Q_{\text {act }}$ were rarely reported.

The flow characteristics and workability of an as-extruded $\mathrm{Mg}-\mathrm{Zn}-\mathrm{Zr}(\mathrm{ZK})$ series alloy during hot deformation was characterized in this work. The isothermal compression tests were conducted at different deformation temperatures and strain rates to investigate the flow characteristics. The constitutive equations improved were derived to predict the response of the material to hot deformation and these were compared with conventional ones. The $3 \mathrm{D}$ activation energy maps were developed to propose the optimal hot processing window for the alloy; the microstructural observation on the compression samples was carried out to reveal the underlying deformation mechanism and verify the validity of activation energy maps. These results can provide guidelines for characterizing and optimizing the hot deformation process of $\mathrm{Mg}$ alloys. 


\section{Experimental methodology}

\subsection{Material preparation}

The studied material in the work is a commercial ZK61 alloy received in as-extruded condition from an industrial company. With reference to the standard of ASTM E209, the isothermal compression samples were designed as cylindrical in shape with dimensions of $\Phi 8 \mathrm{~mm} \times 12 \mathrm{~mm}$. The samples were prepared from the hollow extruded billets with a diameter of $60 \mathrm{~mm}$ and a thickness of 10mm along the extrusion direction (ED) (see Fig. 1). The chemical composition was determined by an inductively coupled plasma-optical emission spectrometer (ICP-OES) (given in Table 1) which is in line with the ASTM B951-11.

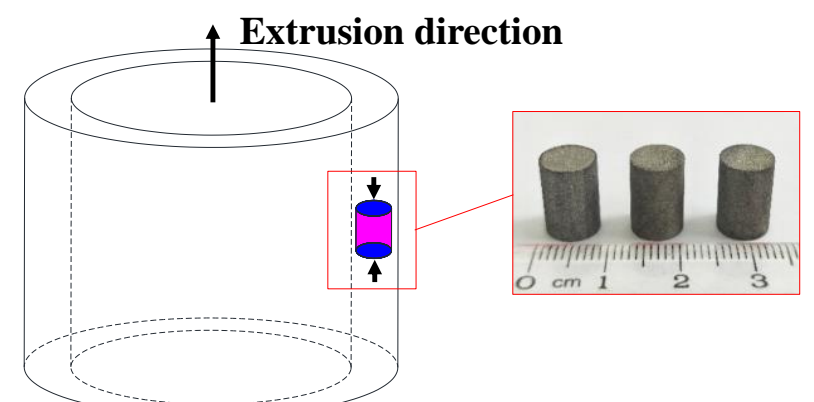

Fig. 1. Sampling method for the isothermal compression. The compression samples were cut from the hollow extruded billets by wire-electrode cutting and ground with grinding wheel to improve the surface finish of samples.

Table 1 Chemical composition of ZK61 alloy (wt.\%).

\begin{tabular}{cccccccccc}
\hline ZK61 & $\mathrm{Zn}$ & $\mathrm{Zr}$ & $\mathrm{Mn}$ & $\mathrm{Fe}$ & $\mathrm{Cu}$ & $\mathrm{Si}$ & $\mathrm{Ni}$ & $\mathrm{Al}$ & $\mathrm{Be}$ \\
\hline Wt.\% & 5.42 & 0.58 & 0.0077 & 0.012 & $<0.0002$ & 0.0022 & $<0.0005$ & 0.0098 & 0.025 \\
\hline
\end{tabular}

\subsection{Isothermal compression tests}

The experimental scheme and device for the isothermal compression are provided in Fig. 2(a) and (b), respectively. To eliminate the thermal gradient prior to the deformation, the compression samples were initially heated to the tested temperature at a heating rate of $10 \mathrm{~K} / \mathrm{s}$ and held for $5 \mathrm{~min}$. The isothermal compression tests were carried out at deformation temperatures from 523 to $673 \mathrm{~K}$ and strain rates from 0.001 to $1 \mathrm{~s}^{-1}$, with a Gleeble-3500 thermo-mechanical simulator. The total height reduction of compression samples was set to be $70 \%$, and each compression sample was water-quenched instantly when the compression test was over to maintain the deformed 
microstructure. To reduce the interference of friction, the top and bottom surfaces of samples were coated with graphite slices, and the interfaces between samples and dies were lubricated by the HW014 Ni-based high temperature lubricant.
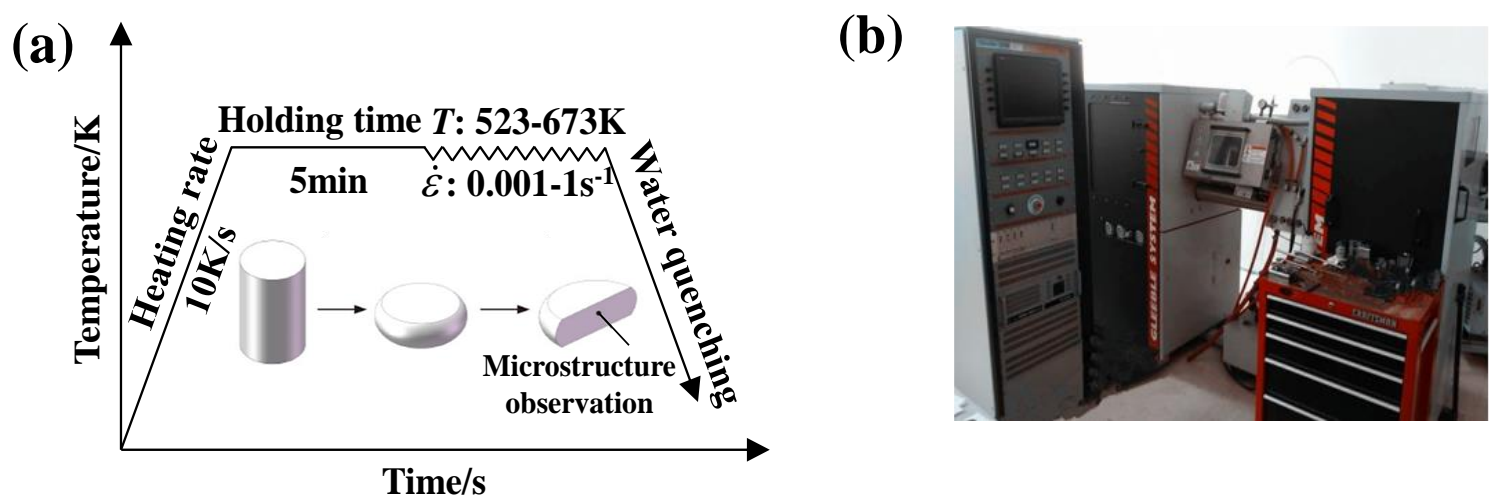

Fig. 2. Isothermal compression: (a) experimental scheme, where the real-time temperature measurement and feedback was realized by thermocouple welded in the center of samples. (b) experimental device, by which the flow stress data were automatically recorded.

\subsection{Microstructure analysis}

The samples for microstructural examinations was performed by optical microscope (OM, Leica DMI5000M). The OM samples were cut along the compression axis and the cut surfaces were ground with $\mathrm{SiC}$ abrasive papers up to a grit of \#1200 and polished with $\mathrm{Al}_{2} \mathrm{O}_{3}$ suspension solution. These were etched with a corrosive solution $(0.8 \mathrm{~g}$ picric acid, $2 \mathrm{ml}$ acetic acid, and $3 \mathrm{ml}$ distilled water). The average grain size was measured by the mean linear intercept method. Also, the existing phases of initial microstructure were identified by X-ray diffraction (XRD, Bruker D8 ADVANCE), and the XRD samples were ground and then polished with the same method adopted by OM.

\section{Results and discussion}

\subsection{Initial microstructure}

The initial microstructure of the as-extruded billet is shown in Fig. 3(a). It can be found that some fine and equiaxed grains can be observed, indicating that the DRX occurs during the hot extrusion process of the alloy. Further, some grains remarkably elongated along the ED exhibit long strip shapes, leading to the inhomogeneous microstructure with an average grain size of $2.5 \mu \mathrm{m}$ as assessed by the linear intercept method. Meanwhile, some granular second phases can be observed 
in the material. In order to further identify the existence of phases, the X-ray diffraction pattern of the alloy is given in Fig. 3(b), where the existence of an intermetallic phase with the stoichiometric composition of $\mathrm{Mg}_{0.97} \mathrm{Zn}_{0.03}$ was confirmed, showing that the $\mathrm{Zn}$ was dissolved into the matrix [30].

(a)

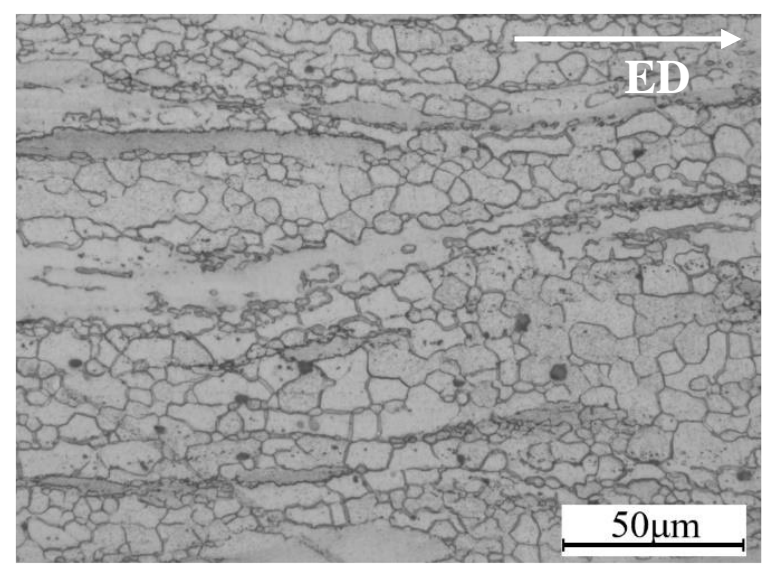

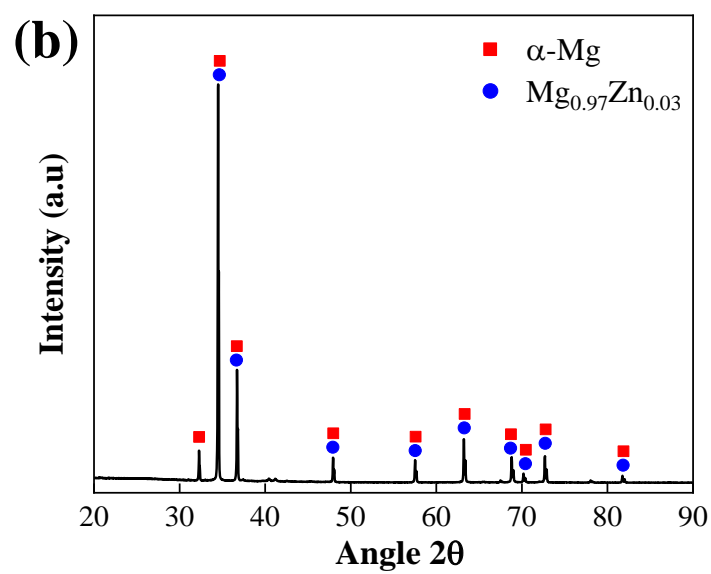

Fig. 3. Microstructure analysis of the as-extruded ZK61 alloy: (a) optical micrograph, where the elongated grains, fine DRX grains and granular second phases can be observed. (b) XRD pattern, where the existence of $\mathrm{Mg}_{0.97} \mathrm{Zn}_{0.03}$ phase in the $\alpha-\mathrm{Mg}$ matrix can be confirmed after extrusion.

\subsection{Flow behaviour of the alloy}

A fundamental understanding of the flow behaviour of the alloy is of critical importance to the improvements of its performance [16]. The flow stress curves for the alloy at different temperatures and strain rates obtained from the isothermal compression tests are shown in Fig. 4. It is observed that the curves display the typical characteristic, i.e., the flow stress increases rapidly in the WH stage, and then reaches at the peak stress, where the softening mechanisms like DRV and DRX play an important role; the flow stress decreases gradually with further increase of strain due to the significant DRX softening. It also can be found that the level of both the peak stress and flow stress decreases remarkably with increasing temperature and decreasing strain rate.

Considering the effect of strain on flow behaviour, the shapes of the flow stress curves after the peak stress can be further generalized in three types: (i) the flow stress decreases continuously and seems to have no steady state (like $523 \mathrm{~K}$ and $0.1-1 \mathrm{~s}^{-1}, 573 \mathrm{~K}$ and $1 \mathrm{~s}^{-1}$ ); (ii) the flow stress decreases to a certain value and remain basically constant (like $523 \mathrm{~K}$ and $0.001-0.01 \mathrm{~s}^{-1}$, $573 \mathrm{~K}$ and $0.001-0.1 \mathrm{~s}^{-1}, 623 \mathrm{~K}$ and $0.1-1 \mathrm{~s}^{-1}, 673 \mathrm{~K}$ and $\left.0.1-1 \mathrm{~s}^{-1}\right)$; and (iii) the flow stress decreases firstly and increases again at large strain (like $623 \mathrm{~K}$ and $0.001-0.01 \mathrm{~s}^{-1}, 673 \mathrm{~K}$ and $0.001-0.01 \mathrm{~s}^{-1}$ ). The similar variations of flow behaviours can be observed in other research [22], but no detailed discussions 
were given.
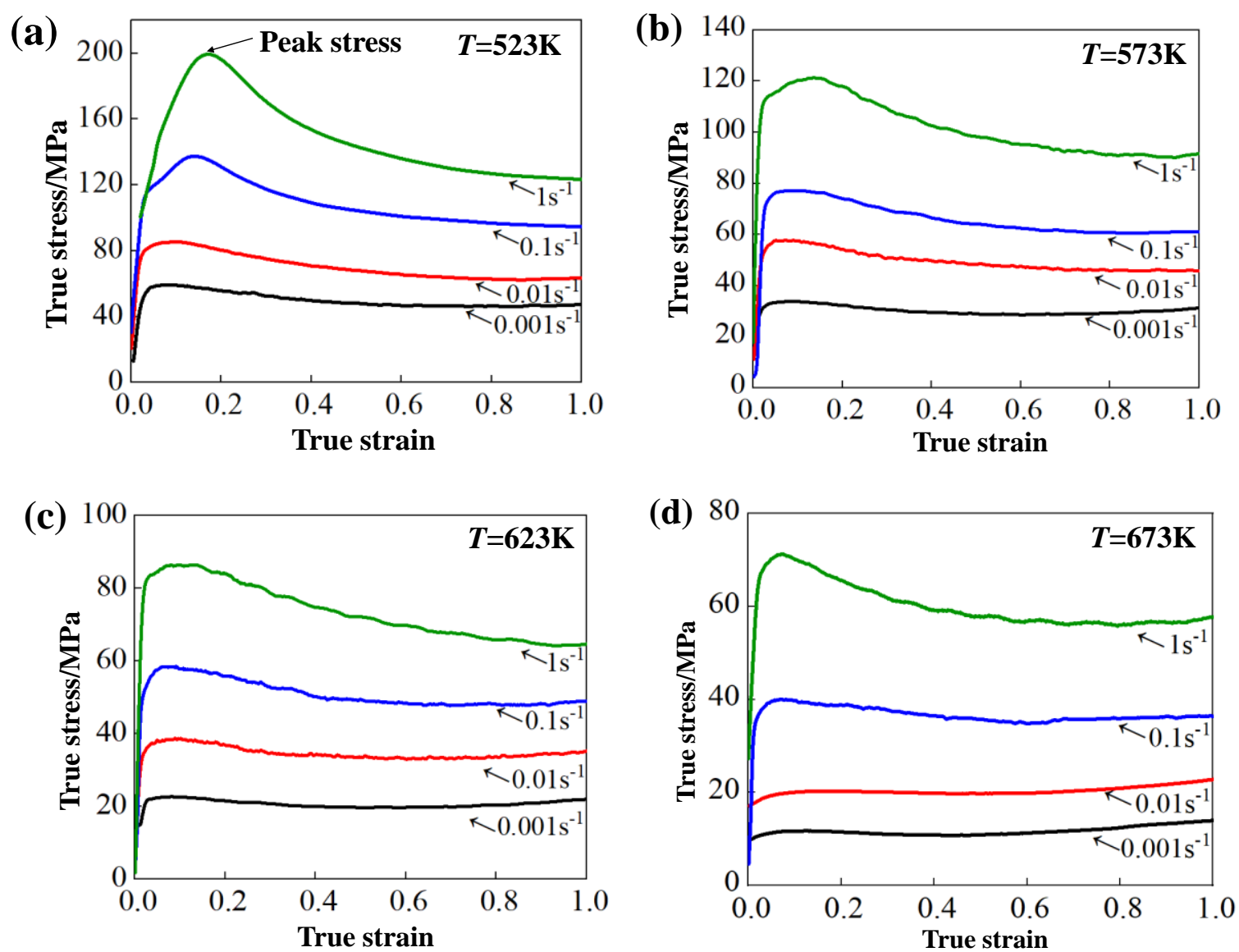

Fig. 4. Flow stress curves of the as-extruded ZK61 alloy at different temperatures of (a) 523K, (b) $573 \mathrm{~K}$, (c) $623 \mathrm{~K}$, (d) $673 \mathrm{~K}$. Each curve with various colors corresponds to a fixed strain rate from $0.001-1 \mathrm{~s}^{-1}$. The values of flow stress exhibit sensitivity to temperature, strain rate and strain.

The variations of the flow stress curves in Fig. 4 can be understood from the perspective of microstructural evolution mechanism [26]. The form (i) occurs noticeably at a low temperature and high strain rate. Meanwhile, the DRX occurs later and is incomplete since some matrix structure still exists at $523 \mathrm{~K} / 0.1 \mathrm{~s}^{-1}$ (Fig. 5(a)), where many DRX grains nucleate at the original boundaries. The increase of the strain rate offers DRX more driving energy and greatly facilitates the nucleation process at $523 \mathrm{~K} / 1 \mathrm{~s}^{-1}$, leading to the necklace-type grain distribution and continuous softening of the flow stress after the peak stress, as shown in Fig. 5(b). In terms of the steady-state flow stress in form (ii), it can be obtained by a dynamic equilibrium among the WH, DRV and DRX, where the effects of WH and softening processes of DRV and DRX cancel out, and the dislocation density remains relatively constant as strain increases.

The form (iii) occurs manifestly at a high temperature and low strain rate. For instance, the 
DRX occurs at grain boundaries followed by obvious grain growth at $673 \mathrm{~K} / 0.001 \mathrm{~s}^{-1}$ (Fig. 5(c)), where a lot of twins are observed. This is because many original grain boundaries are consumed during the softening stage, the nucleation sites decrease rapidly and DRX gets slow; the grain refinement strengthening (GRS) induced by the DRX grains can cause flow hardening, while the occurrence of twins accommodates the deformation. Also, the intersecting twins appear to segment and refine the original grains at $673 \mathrm{~K} / 0.01 \mathrm{~s}^{-1}$ (Fig. $5(\mathrm{~d})$ ), which not only provides more nucleation sites but enhance the hardening behaviour. Although the DRX softening still exists when many fine DRX grains form at grain boundaries as well as twin boundaries, the flow stress continues to increase due to the GRS. Additionally, the Orowan strengthening (OS) may occur due to the interaction between dislocations and $\mathrm{Mg}_{0.97} \mathrm{Zn}_{0.03}$ precipitates as evidenced by XRD analysis (Fig. 3(b)) [31]. These are responsible for the secondary hardening phenomenon at a large strain.

Fig. 5. Optical micrographs of compression samples at different deformation conditions: (a) $523 \mathrm{~K}, 0.1 / \mathrm{s}$, where the matrix structure and incomplete DRX can be observed. (b) $523 \mathrm{~K}, 1 / \mathrm{s}$, where the uneven grain distribution exhibits the necklace-type. (c) $673 \mathrm{~K}, 0.001 / \mathrm{s}$, where the DRX grains grow rapidly and twins occur. (d) $673 \mathrm{~K}, 0.01 / \mathrm{s}$, where the twins interaction increase and grain refinement get obvious.

The flow behaviour of a metallic material which exhibits high strain rate sensitivity is usually related to the superplasticity [32]. In order to characterize the relationship between the flow stress $(\sigma)$ of the alloy and strain rate $(\dot{\varepsilon})$ during hot deformation, the strain rate sensitivity index $m$ was introduced as follows [33]:

$$
\sigma=K \dot{\varepsilon}^{m}
$$

where, $K$ is material constant; the value of $m$ is usually lower than 0.1 for most metallic materials. For the material in a superplastic state, the $m$ lies in the range of $0.3 \sim 0.9$ according to the Newtonian viscous flow [34]. Hence, high strain rate sensitivity is the most essential criterion of superplastic deformation. The value of $m$ can be calculated by:

$$
m=\frac{\log \left(\sigma_{2} / \sigma_{1}\right)}{\log \left(\dot{\varepsilon}_{2} / \dot{\varepsilon}_{1}\right)}
$$

where, $\sigma_{1}$ and $\sigma_{2}$ are the flow stresses corresponding to the same strain, $\dot{\varepsilon}_{1}$ and $\dot{\varepsilon}_{2}$ are the corresponding strain rates of the curves.

The flow stress at the strain of 0.6 under different temperatures and strain rates is shown in 
Table 2. Based on the cubic polynomial fitting, the $m$ values of flow stress at the given strain can be calculated from the curves of $\ln \sigma-\ln \dot{\varepsilon}$ plot (Fig. 6(a)). The variations of $m$ with temperature and strain rate at a constant strain constitutes the strain rate sensitivity map, as shown in Fig. 6(b). It can be seen that the $m$ values change obviously as temperature or strain rate increases, which are remarkably high $(m \geq 0.1)$ at all the given conditions except at the temperature of $523 \mathrm{~K}$ and strain rate of $1 \mathrm{~s}^{-1}$. And the $m$ value is larger than 0.3 in the temperature range of $560 \sim 600 \mathrm{~K}$ and at strain rate of $0.001 \mathrm{~s}^{-1}$, indicating that the alloy exhibits superplastic behaviour during the isothermal compression. This is consistent with the superplasticity of $\mathrm{Mg}-\mathrm{Zn}-\mathrm{Zr}$ alloys reported by Malik et al. [19] and Li et al. [21]. Since the hot workability cannot be completely determined by the shapes of flow stress curves [35], the constitutive behaviour and evolution of activation energy were discussed in the following sections.

Table 2 Flow stress of the ZK61 Mg alloy at a strain of 0.6.

\begin{tabular}{ccccc}
\hline \multirow{2}{*}{ Strain rate/s ${ }^{-1}$} & \multicolumn{5}{c}{ Temperature/K } \\
\cline { 2 - 5 } & 523 & 573 & 623 & 673 \\
\hline 0.001 & 46.8 & 28.5 & 19.7 & 11.2 \\
0.01 & 65.6 & 47.5 & 32.9 & 19.8 \\
0.1 & 100.9 & 62.5 & 48.4 & 34.8 \\
1 & 136.0 & 95.2 & 69.7 & 56.8 \\
\hline
\end{tabular}
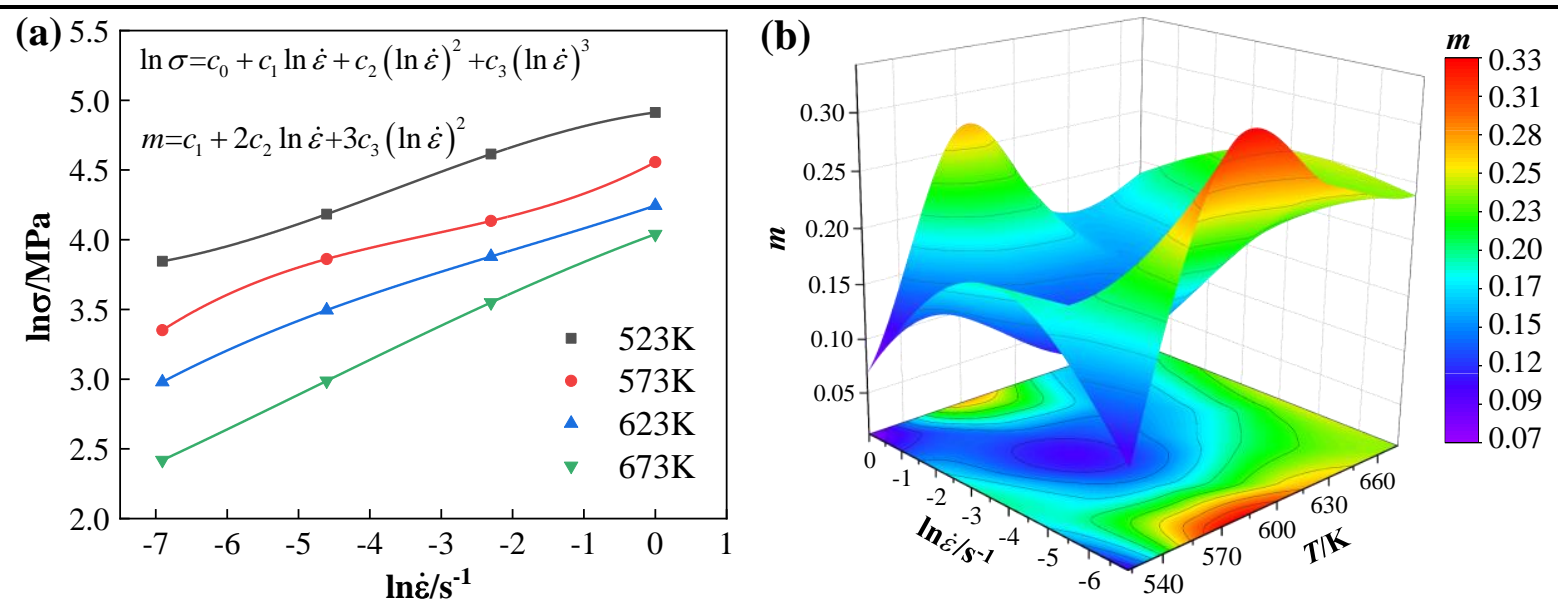

Fig. 6. Calculation and characterization of $m$ value (a) fitting plots of $\ln \sigma$ against $\ln \dot{\varepsilon}$, where the third-order nonlinear relationship between stress and strain rate under different temperatures was fitted in logarithmic operation. (b) strain rate sensitivity map at a constant strain of 0.6 , where the response of $m$ value to temperature and strain rate was obtained based on the slopes of cubic spline curves.

\subsection{Analysis of constitutive behaviour}

\subsubsection{Conventional constitutive equations}


The hot deformation of metals and alloys can be treated as a thermally activated process, while the Arrhenius equation considering the activation energy for deformation is now widely used to demonstrate the simultaneous effects of both deformation temperature, strain rate on the flow stress of materials [36, 37]. Their relationship under all level of flow stress can be mathematically described as follows:

$$
A[\sinh (\alpha \sigma)]^{n}=\dot{\varepsilon} \exp \left(\frac{Q_{a c t}}{R T}\right)
$$

where, $A$ and $n$ are the material parameters, $\alpha$ is the stress multiplier, $R$ is the ideal gas constant $(8.314 \mathrm{~J} / \mathrm{mol} \cdot \mathrm{K})$, and $Q_{\text {act }}$ is the activation energy $(\mathrm{J} / \mathrm{mol})$. The flow stress under a low-stress level $(\alpha \sigma<0.8)$ increases as a power function, while that under a high-stress level $(\alpha \sigma>1.2)$ increases exponentially [38]. Thus, the Eq. (3) can be further generalized as follows:

$$
\begin{gathered}
A_{1} \sigma^{n_{1}}=\dot{\varepsilon} \exp \left(\frac{Q_{a c t}}{R T}\right) \\
A_{2} \exp (\beta \sigma)=\dot{\varepsilon} \exp \left(\frac{Q_{a c t}}{R T}\right)
\end{gathered}
$$

where, $A_{1}, A_{2}, n_{1}, \beta$ are material parameters. The stress multiplier $\alpha$ can be defined as $\alpha=\frac{n_{1}}{\beta}$. Taking the natural logarithm on both sides of Eqs. (4-5), the equations can be derived as follows:

$$
\begin{gathered}
\ln \dot{\varepsilon}=n_{1} \ln \sigma+\left[\ln A_{1}-\frac{Q_{a c t}}{R T}\right] \\
\ln \dot{\varepsilon}=\beta \sigma+\left[\ln A_{2}-\frac{Q_{a c t}}{R T}\right]
\end{gathered}
$$

Normally, the peak flow stress data is adopted to calculate the material parameters in constitutive modelling of metals and alloys [39], and the peak stress $\sigma_{\mathrm{p}}$ referring to a dynamic equilibrium between the hardening influence and the dynamic restoration occurred when the strain hardening rate $\theta=\frac{\partial \sigma}{\partial \varepsilon}=0$ [40]. According to Eqs. (6-7), the plots of $\ln \dot{\varepsilon}-\ln \sigma_{p}$ and $\ln \dot{\varepsilon}-\sigma_{p}$ under various temperatures are given, as shown in Fig. 7(a) and (b). The values of $n_{1}$ and $\beta$ can be obtained via the mean slopes of the lines, which were calculated as 4.531 and $0.081 \mathrm{MPa}^{-1}$, respectively. And then the value of $\alpha$ can be obtained as $0.018 \mathrm{MPa}^{-1}$. 

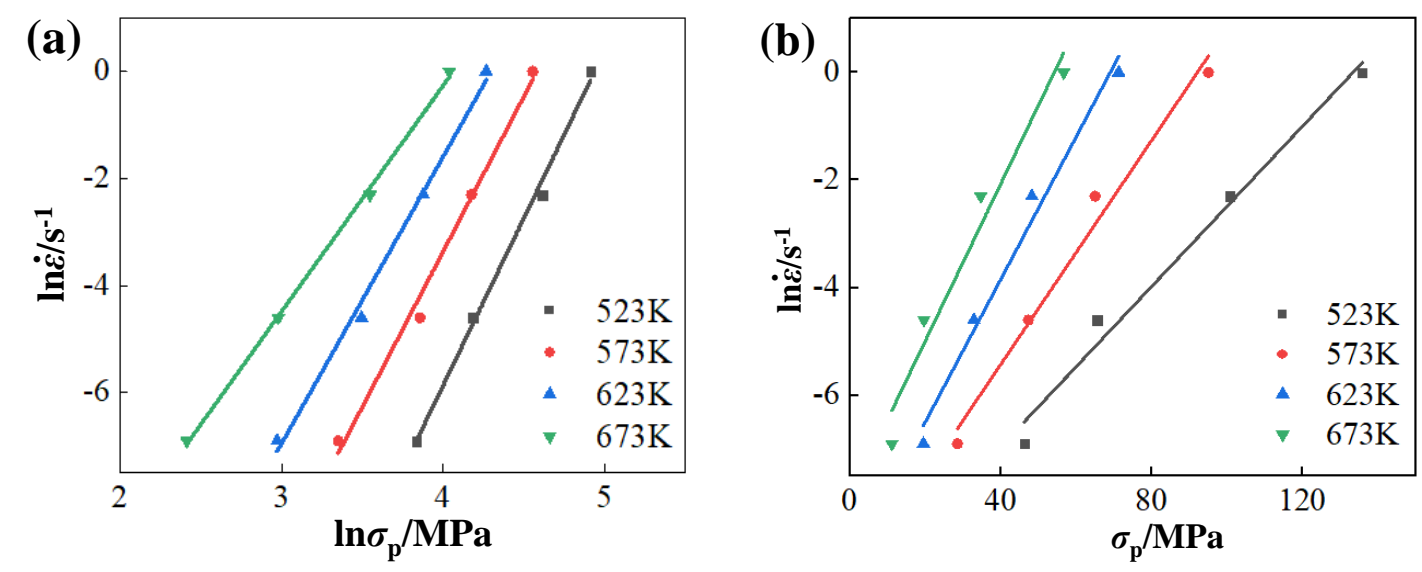

Fig. 7. Fitting plots of (a) $\ln \dot{\varepsilon}$ against $\ln \sigma_{p}$, where the $n_{1}$ value can be calculated by the mean slopes of the lines. (b) $\ln \dot{\varepsilon}$ against $\sigma_{p}$, where the $\beta$ value can be calculated by the mean slopes of the lines. The ratio of $n_{1}$ value to $\beta$ value was calculated to obtain the $\alpha$ value.

Taking the natural logarithm on both sides of Eq. (3) gives:

$$
\ln \dot{\varepsilon}=n \ln [\sinh (\alpha \sigma)]+\left[\ln A-\frac{Q_{a c t}}{R T}\right]
$$

Then, the value of $Q_{\text {act }}$ can be determined by differentiating Eq. (8) at given temperature and strain rate, respectively. The corresponding equations are derived as follows:

$$
\begin{gathered}
n=\left[\frac{\partial \ln \dot{\varepsilon}}{\partial \ln [\sinh (\alpha \sigma)]}\right]_{T} \\
Q_{a c t}=R n\left[\frac{\partial \ln [\sinh (\alpha \sigma)]}{\partial(1 / T)}\right]_{\dot{\varepsilon}}=R n s
\end{gathered}
$$

The relationships of $\ln \dot{\varepsilon}-\ln \sinh \left(\alpha \sigma_{\mathrm{p}}\right)$ and $\ln \left[\sinh \left(\alpha \sigma_{\mathrm{p}}\right)\right]-1000 / T$ can be plotted on the basis of the experimental data of flow stress, as shown in Fig. 8(a) and (b), where the mean slopes of these parallel straight lines can give the approximate values of $n$ and $s$ at specific temperature and strain rate, respectively. And thus the average $Q_{\text {act }}$ value was calculated as $120.11 \mathrm{~kJ} / \mathrm{mol}$ according to the Eqs. (9-10). Combining the Zener-Holloman parameter $\left(Z=\dot{\varepsilon} \exp \left(\frac{Q_{a c t}}{R T}\right)\right)$ [41] with the Eq. (3), the following expression can be obtained as follows: 

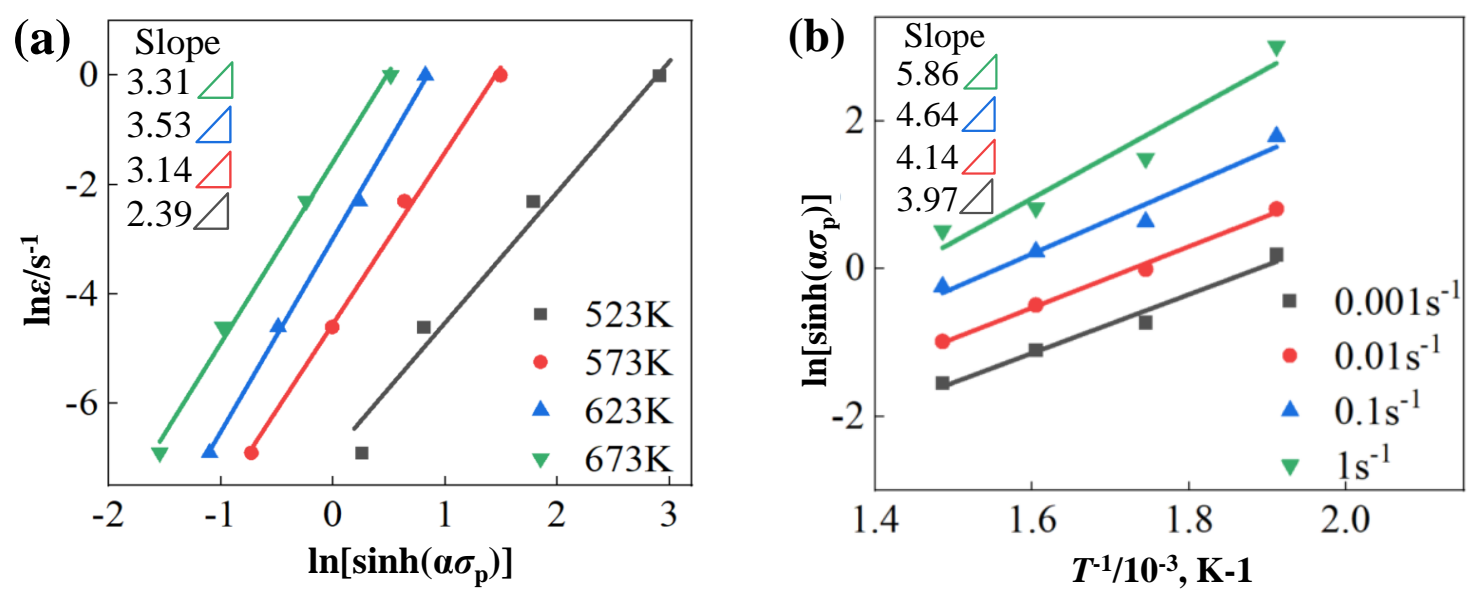

Fig. 8. Fitting plots of (a) $\ln \dot{\varepsilon}$ against $\ln \left[\sinh \left(\alpha \sigma_{p}\right)\right]$, where the $n$ value can be calculated by the mean slopes of the lines; (b) $\ln [\sinh (\alpha \sigma)]$ against $T^{1}$, where the $s$ value can be calculated by the mean slopes of the lines. The product of $n, s$ and $R$ was calculated to obtain the $Q_{\text {act }}$ value.

$$
Z=A[\sinh (\alpha \sigma)]^{n}
$$

Taking the natural logarithm on both sides of Eq. (11) gives:

$$
\ln Z=\ln A+n \ln [\sinh (\alpha \sigma)]
$$

Based on the obtained values of $\alpha$ and $Q_{\text {act }}$ above, the relationship between $\ln Z$ and $\ln [\sinh (\alpha \sigma)]$ was plotted in Fig. 9, where the slope and intercept of the straight line offers the values of $n$ and $\ln A$, respectively. It can be seen that the calculated stress exponent $n=3.137$ and material parameter $A=5.621 \times 10^{8}$. The rate controlling mechanisms during hot deformation of the alloy can be deduced from the values of $Q_{\text {act }}$ and $n$ [42]. The obtained $Q_{\text {act }}$ is smaller than the lattice self-diffusion activation energy of $\mathrm{Mg}(135 \mathrm{~kJ} / \mathrm{mol})$ and the $n$ is within the range of $3 \sim 3.5$, which implies that the hot deformation of the alloy relating to the gliding and climbing of dislocations is gliding-controlled (i.e., viscous gliding) $[43,44]$. Thus, the conventional Arrhenius equations used for predicting the peak flow stress can be obtained which is expressed as follows:

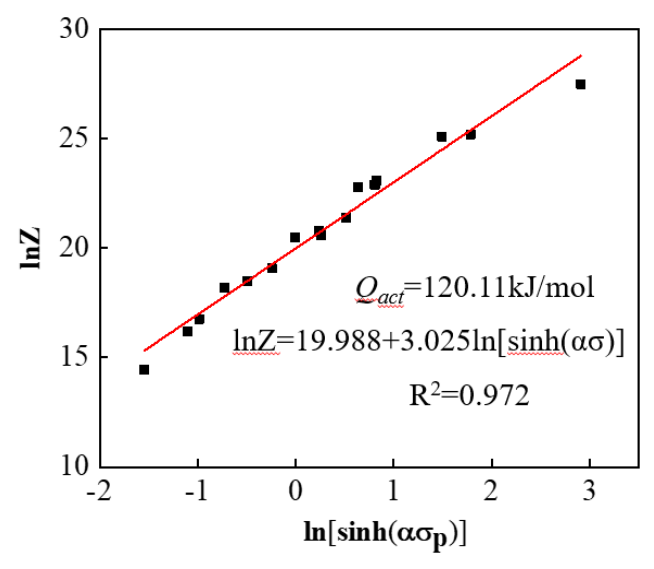


Fig. 9. Fitting plot of $\ln [\sinh (\alpha \sigma)]$ against $\ln Z$, where the $n$ value can be obtained from the slope of the line and the $\ln A$ value can be obtained from the intercept of the line.

$$
\left\{\begin{array}{l}
\sigma_{P}=\frac{1}{0.018} \ln \left[\left(\frac{Z}{4.795 \times 10^{8}}\right)^{1 / 3.025}+\sqrt{\left(\frac{Z}{4.795 \times 10^{8}}\right)^{2 / 3.025}+1}\right] \\
Z=\dot{\operatorname{e}} \exp \left(\frac{120110}{R T}\right)
\end{array}\right.
$$

The values of material parameters including $Q_{\text {act }}$ obtained in this Section are average values and independent from deformation parameters due to simplifications. It is worth noting that the values of $n$, i.e., the slopes of the $\ln \dot{\varepsilon}-\ln \sinh \left(\alpha \sigma_{\mathrm{p}}\right)$ curve at specific temperature, are obviously different in the isothermal compression test (Fig. 8(a)), and thus $n$ is dependent on the temperature $[14,15,18,19,22,23]$. Similarly, the value of $s$, i.e., the slopes of the $\ln \left[\sinh \left(\alpha \sigma_{\mathrm{p}}\right)\right]-T^{-1} / 10^{-3}$ curve at specific strain rate, varies in the experimental data (Fig. 8(b)), indicating that $s$ is strain rate dependent $[14,15,16,18,19,22,23]$. Meanwhile, it is well known that hot deformation of metallic materials occurs mainly by dislocation motion which is a thermally activated mechanism. The increase of temperature and applied external stress both can make dislocation move with faster kinetics, making the deformation easy and the $Q_{\text {act }}$ reduced [45]. Therefore, the conventional constitutive equations cannot adequately describe the hot flow behaviour of the alloy.

\subsubsection{Improved constitutive equations}

Considering the effects of deformation parameters on flow behaviour, the $n$ was assumed as a function of temperature and $Q_{\text {act }}$ was regarded as a material variable that is dependent on temperature and strain rate, while the $A$ was supposed as a function of temperature and strain rate. The Arrhenius-type equation can be thus written as follows:

$$
A(T, \dot{\varepsilon})[\sinh (\alpha \sigma)]^{n(T)}=\dot{\varepsilon} \exp \left(\frac{Q_{a c t}(T, \dot{\varepsilon})}{R T}\right)
$$

By applying natural logarithm on both sides of Eq. (14) gives:

$$
\ln \dot{\varepsilon}=n(T) \ln [\sinh (\alpha \sigma)]+\left[\ln A(T, \dot{\varepsilon})-\frac{Q_{a c t}(T, \dot{\varepsilon})}{R T}\right]
$$

Consequently, the $n(T)$ values can be calculated from the slopes of $\ln \dot{\varepsilon}-\ln [\sinh (\alpha \sigma)]$ plots at a given temperature (Fig.8 (a)), and an excellent polynomial relationship between $n$ and the 
temperature can be obtained by regression fitting, as shown in Fig. 10(a). It is clear that $n$ is not a material constant, which increases firstly and then decreases with the increase of temperature. This indicates that $n$ has high temperature sensitivity.

The $Q_{a c t}(T, \dot{\varepsilon})$ values can be determined by taking partial derivatives of both sides of Eq. (15) at a constant strain rate, and corresponding equation can be derived as follows:

$$
\begin{gathered}
Q_{a c t}(T, \dot{\varepsilon})=R n(T)\left[\frac{\partial \ln [\sinh (\alpha \sigma)]}{\partial(1 / T)}\right]_{\dot{\varepsilon}}+\left\{R \ln [\sinh (\alpha \sigma)]\left[\frac{\partial n(T)}{\partial(1 / T)}\right]_{\dot{\varepsilon}}+R\left[\frac{\partial \ln A(T, \dot{\varepsilon})}{\partial(1 / T)}\right]_{\dot{\varepsilon}}-\frac{1}{T}\left[\frac{\partial Q(T, \dot{\varepsilon})}{\partial(1 / T)}\right]_{\dot{\varepsilon}}\right\} \quad \text { (16) } \\
\text { In general, the term } P=\left\{R \ln [\sinh (\alpha \sigma)]\left[\frac{\partial n(T)}{\partial(1 / T)}\right]_{\dot{\varepsilon}}+R\left[\frac{\partial \ln A(T, \dot{\varepsilon})}{\partial(1 / T)}\right]_{\dot{\varepsilon}}-\frac{1}{T}\left[\frac{\partial Q(T, \dot{\varepsilon})}{\partial(1 / T)}\right]_{\dot{\varepsilon}}\right\} \quad \text { can be }
\end{gathered}
$$

regarded as zero [46], so the $P \approx 0$ in this study and the validity of this assumption will be verified later. Therefore, the Eq. (16) can be simplified and expressed as follows:

$$
Q_{a c t}(T, \dot{\varepsilon})=R n(T)\left[\frac{\partial \ln [\sinh (\alpha \sigma)]}{\partial(1 / T)}\right]_{\dot{\varepsilon}}=R n(T) s(\dot{\varepsilon})
$$

According to the values of $s(\dot{\varepsilon})$ calculated from the slopes of $\ln \dot{\varepsilon}-\ln [\sinh (\alpha \sigma)]$ plots at a constant strain rate (Fig. 8(b)), a good polynomial relationship between $s(\dot{\varepsilon})$ and strain rate can be obtained by regression fitting, as shown in Fig. 10(b). Substituting the values of $n(T)$ and $s(\dot{\varepsilon})$ in Fig. 10 into Eq. (17), and the activation energy of deformation $Q_{\text {act }}(T, \dot{\varepsilon})$ as function of the natural logarithm of strain rate and temperature can be expressed as follows:
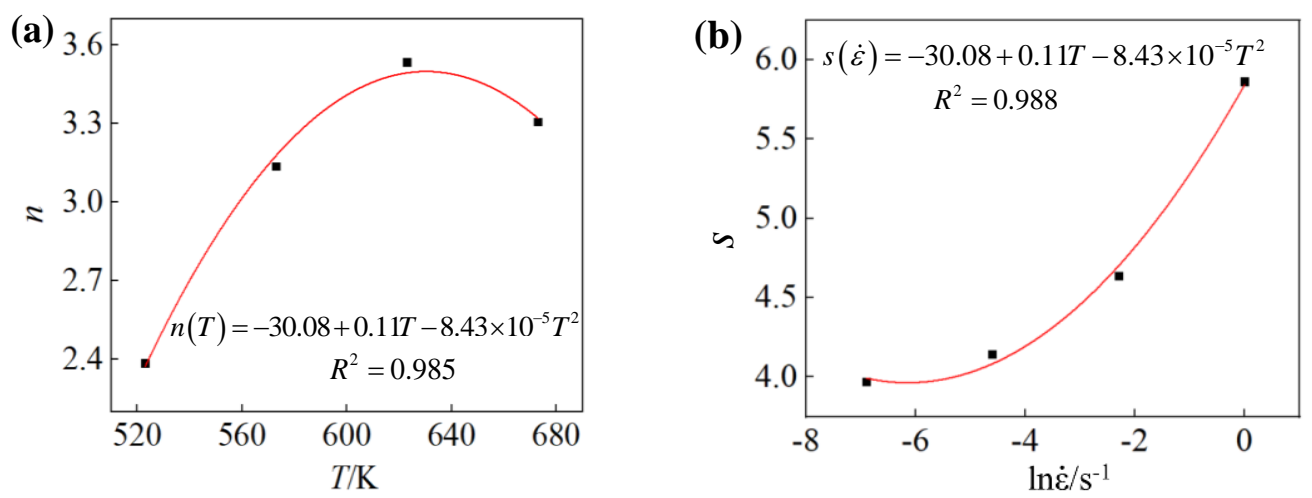

Fig. 10. Relationships between (a) $n$ and $T$, where the $n$ value exhibits obvious dependency on temperature and the response of $n$ value to temperature is obtained. (b) $s$ and $\ln \dot{\varepsilon}$, where the $s$ value exhibits dependency on strain rate and the response of $s$ value to strain rate is obtained. 


$$
\begin{aligned}
& Q_{a c t}(T, \dot{\varepsilon})=-175.97-19.24(\ln \dot{\varepsilon})-1.70(\ln \dot{\varepsilon})^{2}+0.62 T+0.07 T(\ln \dot{\varepsilon})+ \\
& 6.01 \times 10^{-3} T(\ln \dot{\varepsilon})^{2}-4.93 \times 10^{-4} T^{2}-5.39 \times 10^{-5} T^{2}(\ln \dot{\varepsilon})-4.76 \times 10^{-6} T^{2}(\ln \dot{\varepsilon})^{2}
\end{aligned}
$$

Combining with the Eq. (15), the value of $\left[\ln A(T, \dot{\varepsilon})-Q_{a c t}(T, \dot{\varepsilon}) / R T\right]$ can be calculated using the intercepts of $\ln \dot{\varepsilon}-\ln [\sinh (\alpha \sigma)]$ plots at a constant temperature. Furthermore, the values of $Q_{a c t}(T, \dot{\varepsilon})$ can be calculated from Eq. (18), thus the response of $\ln A(T, \dot{\varepsilon})$ to temperature and strain rate is expected to be similar to that of $Q_{a c t}(T, \dot{\varepsilon})$. Accordingly, the values of $\ln A$ at different temperature and strain rate are shown in Fig. 11, the $\ln A$ tends to increase as strain rate increase, while it increases firstly and decreases as temperature increases. To extract a formula for $\ln A(T, \dot{\varepsilon})$, a polynomial fitting is successfully applied between $\ln A$ and $T, \dot{\varepsilon}$ with a correlation coefficient of $R^{2}=0.997$, and the expression of $\ln A$ can be described as follows:

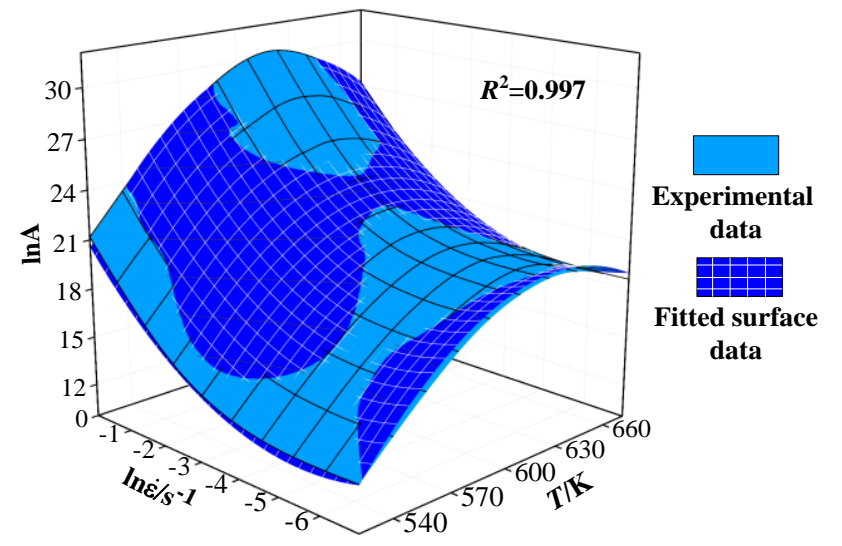

Fig. 11. Evolution of $\ln A$ value as a function of $T, \dot{\varepsilon}$, where the $\ln A$ value exhibits high dependency on temperature and strain rate, and a 3D polynomial surface fit was used to parameterize experimental data with $R^{2}=0.997$.

$$
\begin{aligned}
& \ln A(T, \dot{\varepsilon})=-350.23-34.57(\ln \dot{\varepsilon})-3.33(\ln \dot{\varepsilon})^{2}+1.22 T+0.13 T(\ln \dot{\varepsilon})+ \\
& 0.01 T(\ln \dot{\varepsilon})^{2}-9.86 \times 10^{-4} T^{2}-1.05 \times 10^{-4} T^{2}(\ln \dot{\varepsilon})-1.01 \times 10^{-5} T^{2}(\ln \dot{\varepsilon})^{2}
\end{aligned}
$$

According to the performed calculations above, the peak flow stress of this alloy under different strain rates and deformation temperatures can be described by the improved Arrhenius constitutive equations, which can be calculated as follows: 


$$
\left\{\begin{array}{l}
\sigma_{p}=\frac{1}{\alpha} \sinh ^{-1}\left[\frac{\dot{\varepsilon} \exp \left(Q_{\text {act }}(T, \dot{\varepsilon}) / R T\right)}{A(T, \dot{\varepsilon})}\right]^{1 / n(T)} \\
\alpha=0.02 \\
n(T)=-30.08+0.11 T-8.43 \times 10^{-5} T^{2} \\
Q_{a c t}(T, \dot{\varepsilon})=-175.97-19.24(\ln \dot{\varepsilon})-1.70(\ln \dot{\varepsilon})^{2}+0.62 T+0.07 T(\ln \dot{\varepsilon})+ \\
6.01 \times 10^{-3} T(\ln \dot{\varepsilon})^{2}-4.93 \times 10^{-4} T^{2}-5.39 \times 10^{-5} T^{2}(\ln \dot{\varepsilon})-4.76 \times 10^{-6} T^{2}(\ln \dot{\varepsilon})^{2} \\
\ln A(T, \dot{\varepsilon})=-350.23-34.57(\ln \dot{\varepsilon})-3.33(\ln \dot{\varepsilon})^{2}+1.22 T+0.13 T(\ln \dot{\varepsilon})+ \\
0.01 T(\ln \dot{\varepsilon})^{2}-9.86 \times 10^{-4} T^{2}-1.05 \times 10^{-4} T^{2}(\ln \dot{\varepsilon})-1.01 \times 10^{-5} T^{2}(\ln \dot{\varepsilon})^{2}
\end{array}\right.
$$

Noticeably, the value of $P$ term in Eq. (16) can be calculated on the basis of Eq. (20) and compared with the experimental data within the deformation conditions, and the ratios of obtained values of $P$ to those of $Q_{\text {act }}$ are in the ranges of $0.007 \sim 0.0385$, which are quite small. It is therefore acceptable to treat the term $P$ as zero to simplify the calculation of $Q_{\text {act. }}$.

\subsubsection{Verification of the developed equations}

To verify the validity of conventional and improved Arrhenius constitutive equations, the experimental peak stress and predicted results obtained by two kinds of equations at different deformation parameters were compared in Fig. 12. It can be observed that the conformity between the peak stresses predicted by conventional equations and those of experiment is not desirable (Fig. 12(a)). More specifically, the maximum peak stress in experiment reaches 199.3 MPa, while that obtained by conventional equations is only 178.8 MPa. Meanwhile, a good excellent agreement can be found between the experimental results and the peak stress values predicted by the improved constitutive equations, and the predicted maximum peak stress of $193.1 \mathrm{MPa}$ is quite close to the experimental value (Fig. 12(b)). This indicates that the improved constitutive equations proposed in this study are more reliable for characterizing the flow behaviour of the alloy. 

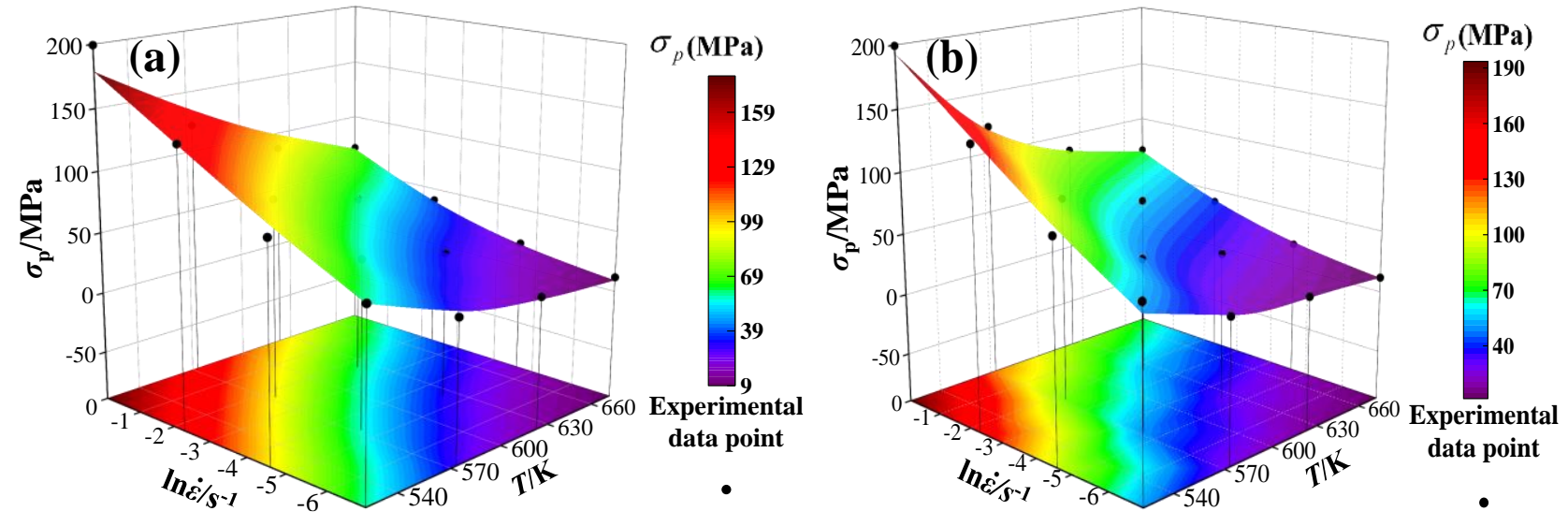

Fig. 12. Comparison between the experimental and predicted peak flow stress values: (a) Conventional constitutive equations, the predicted results of which cannot conform well with the experimental data points. (b) Improved constitutive equations, by which the experimental data points can be accurately predicted.

For quantitative characterization of their prediction performance, the correlation coefficient $\left(R^{2}\right)$, root mean square error $(R M S E)$ and average absolute relative error $(A A R E)$ are used for quantitatively characterizing the accuracy of the flow behaviour. The $R^{2}$ is applied for reflecting the strength of the linear relationship between the experimental and predicted results [47], but a large $R^{2}$ value may not represent a good performance since the trend of the constitutive modelling can be affected by larger or smaller $R^{2}$ [11]. Also, the low RMSE and AARE are commonly used to indicate that the prediction accuracy of the constitutive equations is acceptable.

$$
\begin{gathered}
R^{2}=\frac{\sum_{i=1}^{N}\left(E_{i}-\bar{E}\right)\left(P_{i}-\bar{P}\right)}{\sqrt{\sum_{i=1}^{N}\left(E_{i}-\bar{E}\right)^{2} \sum_{i=1}^{N}\left(P_{i}-\bar{P}\right)^{2}}} \\
\operatorname{RMSE}=\sqrt{\frac{1}{N} \sum_{i=1}^{N}\left(E_{i}-P_{i}\right)^{2}} \\
\operatorname{AARE}(\%)=\frac{1}{N} \sum_{i=1}^{N}\left|\frac{E_{i}-P_{i}}{E_{i}}\right| \times 100 \%
\end{gathered}
$$

where, $E_{\mathrm{i}}$ and $P_{\mathrm{i}}$ are the experimental and predicted flow stresses at a certain strain, respectively. $\bar{E}$ and $\bar{P}$ are the average experimental and predicted flow stress within the studied conditions. $N$ is the total number of data points.

The correlation between the experimental and predicted peak stress values can be seen from Fig. 13 (a) and (b), respectively. The $R^{2}, R M S E$ and $A A R E(\%)$ for the conventional constitutive modelling are $0.967,8.806 \mathrm{MPa}$ and $9.706 \%$. It can be explained by the fact that the variations of 
material parameters under the applied deformation conditions are inevitable and cannot be regarded as constants. While the $R^{2}, R M S E$ and $A A R E(\%)$ for the improved constitutive equations are 0.993 , 4.172Mpa and $4.686 \%$, respectively. This means that the improved constitutive equations have a higher prediction accuracy. Meanwhile, new compression tests were conducted under strain rates of $0.001,0.01,0.1,1 \mathrm{~s}^{-1}$ at temperature of $598 \mathrm{~K}$ to further verify the predictability of the developed constitutive equations. The experimental data which have not been used to calibrate the equations were obtained and compared with the predicted peak flow stress, as shown in Fig. 14. Combining with the Eqs. (22) and (23), the RMSE and $A A R E(\%)$ for the improved constitutive equations are 1.532MPa and $7.778 \%$, while those for the conventional constitutive equations are $7.488 \mathrm{MPa}$ and $7.835 \%$. Therefore, the efficiency of the improved constitutive equations proposed in this study is quite acceptable and it has a better predictability for the flow behaviour.
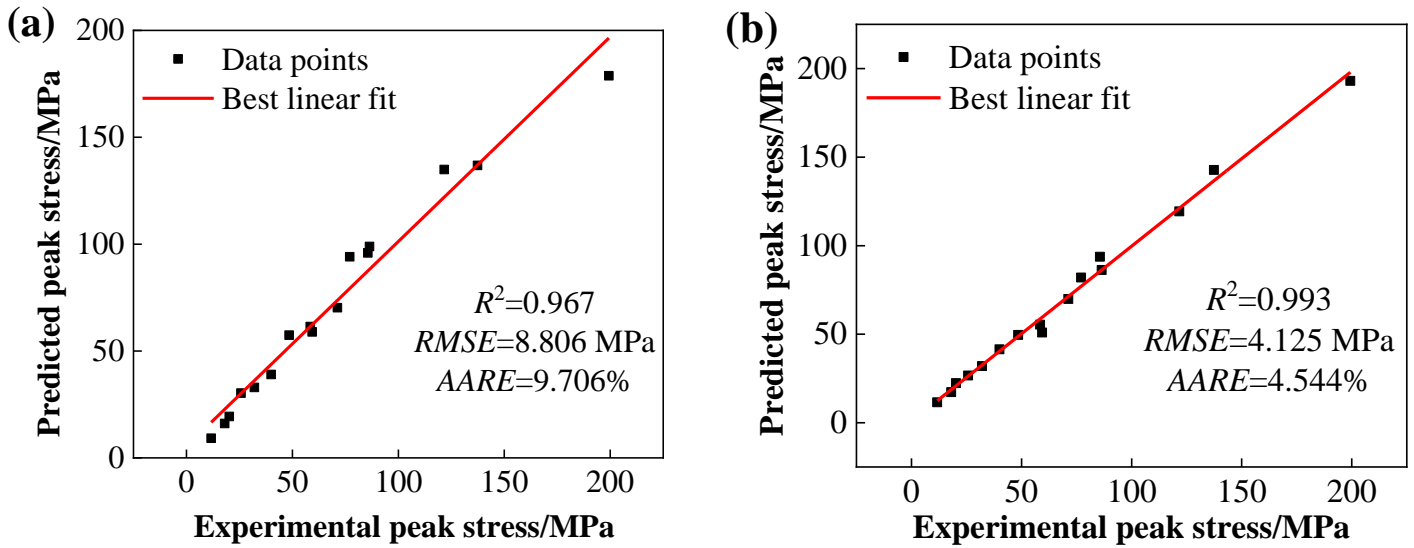

Fig. 13. Correlation between the experimental and predicted peak flow stress values:

(a) Conventional constitutive equations, which has large $R^{2}$ but high $R M S E$ and AARE(\%), indicating an undesirable modelling. (b) Improved constitutive equations, which has larger $R^{2}$ as well as lower $R M S E$ and $A A R E(\%)$, indicating an excellent modelling.

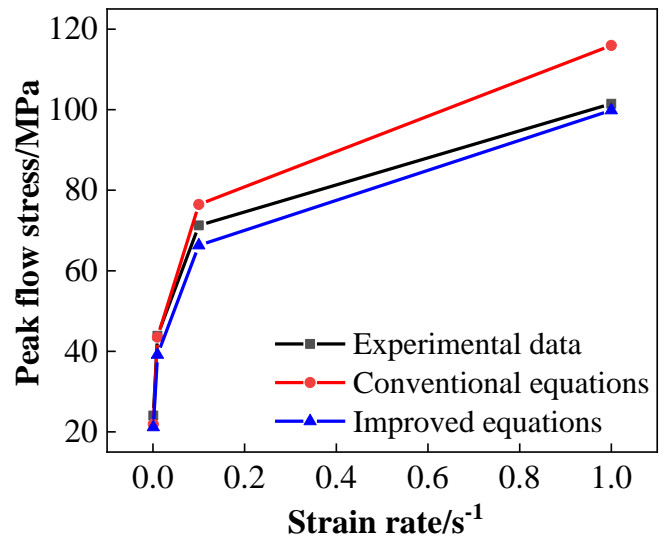

Fig. 14. Comparison between experimental and predicted peak stress under strain rates from 0.001 to $1 \mathrm{~s}^{-1}$ at temperature of $598 \mathrm{~K}$, where the deviations between predicted and experimental results for conventional constitutive equations are largers than those for improved constitutive equations. 


\subsection{Evolution of activation energy}

\subsubsection{Activation energy at the peak strain}

It is well known that the activation energy $Q_{\text {act }}$ obtained by the kinetic analysis describes the energy barrier for dislocation motion and indicates the deformation resistance of materials [48]. The $Q_{\text {act }}$ can be thus used as an indicator for selecting proper deformation parameters and optimizing hot deformation process [49]. Based on the improved constitutive equations in Eq. (20), the activation energy map of the alloy at the peak strain under different strain rate and temperature can be obtained, as shown in Fig. 15. It can be seen that the average $Q_{\text {act }}$ value under all the deformation conditions $(123.23 \mathrm{~kJ} / \mathrm{mol})$ is quite close to that obtained by conventional constitutive equation in Eq. (13), but the $Q_{\text {act }}$ value at the peak strains change greatly with increase of temperatures and strain rates. The $Q_{\text {act }}$ can reach $170.81 \mathrm{~kJ} / \mathrm{mol}$ at the deformation condition of $623 \mathrm{~K} / 1 \mathrm{~s}^{-1}$, while it decreases to $86.23 \mathrm{~kJ} / \mathrm{mol}$ at $523 \mathrm{~K} / 0.001 \mathrm{~s}^{-1}$. This further verifies that $Q_{\text {act }}$ is sensitive to the thermo-mechanical parameters. Also, the experimental data were superposed on the map in Fig.15, which exhibits a good agreement between the experimental results and those predicted by the improved constitutive equations.

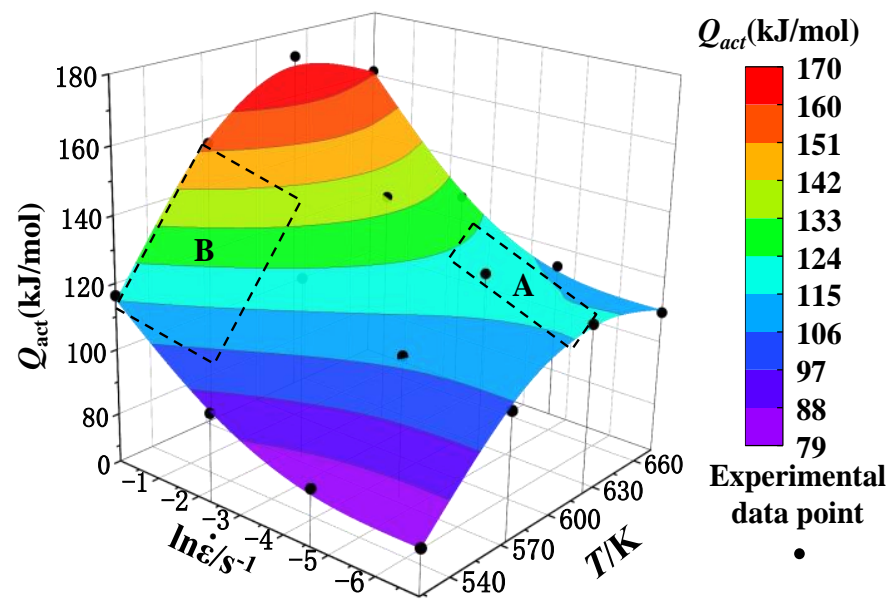

Fig. 15. Activation energy of the as-extruded ZK61 alloy at the peak strain, where the variations of $Q_{\text {act }}$ value are greatly influenced by the applied thermomechanical factors, like temperature and strain rate, and the predicted values of $Q_{\text {act }}$ agree well with experimental data.

According to the concept of activation energy, Malas proposed that the activation energy map can be established to verify the processing window for hot working, and the region where the $Q_{\text {act }}$ value remains steady can be regarded as the desirable region for safe working [50]. It can be also observed from Fig. 15 that a plateau of $Q_{\text {act }}$ exhibits when the alloy is deformed in the region A with 
high temperature $(610 \sim 650 \mathrm{~K})$ and low strain rate $\left(0.001-0.02 \mathrm{~s}^{-1}\right)$, the $Q_{\text {act }}$ only varies within a small range of $115 \sim 124 \mathrm{~kJ} / \mathrm{mol}$. The microstructure deformed at $623 \mathrm{~K} / 0.001 \mathrm{~s}^{-1}$ in region A was given in Fig. 16(a), where the complete DRX is realized and the microstructure with uniform and equiaxed DRX grains can be observed. This indicates that the alloy under safe region has a good workability. Meanwhile, the variations of $Q_{\mathrm{act}}$ ranging from $79 \sim 170 \mathrm{~kJ} / \mathrm{mol}$ is remarkable in other deformation conditions, which could probably correspond to the instability region [25]. For example, the microstructure in region $\mathrm{B}$ with low temperature $(523 \sim 573 \mathrm{~K})$ and high strain rate $\left(0.1-1 \mathrm{~s}^{-1}\right)$ exhibits flow localization (Fig. 16(b)), which tends to be the preferential places for microcracking and not beneficial for the plastic deformation [51].

Fig. 16. Optical micrographs for the deformed samples at different deformation conditions: (a) $623 \mathrm{~K}, 0.001 / \mathrm{s}$ (safe region), where microstructure associated with the region confirmed the occurrence of DRX. (b) $573 \mathrm{~K}, 1 / \mathrm{s}$ (instability region), where the formation of flow localisation corresponding to the region can be observed.

\subsubsection{Effect of strain rate on activation energy}

The flow behaviour of $\mathrm{Mg}$ alloys changes remarkably with strains based on the analysis in Section 3.2. Hence, it is of significance to develop the activation energy maps involving the strain, strain rate and temperature for materials with high strain sensitivity. A series of $Q_{\text {act }}$ values at different temperatures $(523 \sim 673 \mathrm{~K})$, strain rates $\left(0.001-1 \mathrm{~s}^{-1}\right)$ and strains (from 0.1 to 1 with an interval of 0.1) was obtained using the method in Section 3.3. In addition, the relationship of $Q_{\text {act }}$ and strain can be also polynomial fitted [52,53], and a corresponding constitutive equation of the alloy with strain compensation was developed based on the flow stress data from the previous work [54]. The 3D activation energy maps were thus developed on the basis of these values to analyze the evolution of $Q_{\text {act }}$ under different deformation conditions comprehensively.

It is worth noting that the $Q_{\text {act }}$ is related to the interaction of potentially mobile dislocations with other dislocations, solute or precipitates, grain boundaries, or the periodic friction of the lattice which the rate flow, and the yield strength at a constant rate [55]. The relationship between the strain rate and density of mobile dislocations $\rho$ during deformation can be described as follows [56]:

$$
\dot{\varepsilon}=K \rho b \bar{v}
$$

where, $K$ is the material constant, $b$ is the Burgers' vector of dislocation and $\bar{v}$ is the mean speed of dislocations motion through a field of obstacles. 
Combining the Eqs. (17) and (24), it can be known that the $Q_{\text {act }}$ is associated with dislocation density. The evolution of $Q_{\text {act }}$ under different strain rates is shown in Fig. 17. It can be seen that the $Q_{\text {act }}$ decreases firstly and increases rapidly with the increase of strain rate, and the minimum value of $Q_{\text {act }}$ tends to occur at the strain rate of $0.01 \mathrm{~s}^{-1}$. It is because that the dynamic restoration (DRV and DRX) can be accelerated and even become dominant as strain rates increase, which is helpful to decrease the dislocation density. Also, the applied external stress as well as the resolved shear stress can be augmented via the increase of strain rate, resulting in the enhancement of dislocation motion and reduction of thermal energy for overcoming the energy barrier. Thus the slight decrease of $Q_{\text {act }}$ occurs at strain rates of $0.001-0.01 \mathrm{~s}^{-1}$. And the dislocation tanglement can be aggravated by a further increase of strain rates, which increases the energy barrier. Also, increasing strain rate provides little time for dynamic restoration and makes dislocation motion difficult since the dislocations can be severely multiplied, and an incremental trend in $Q_{\text {act }}$ can be observed from $0.01-1 \mathrm{~s}^{-1}$. Therefore, the lower strain rates $\left(0.001-0.01 \mathrm{~s}^{-1}\right)$ are beneficial for the decrease of $Q_{\mathrm{act}}$ and the occurrence of DRX.

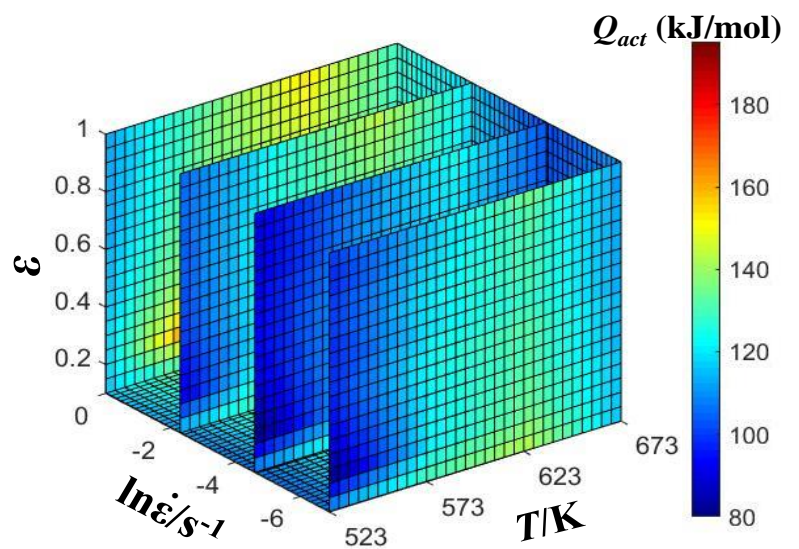

Fig. 17. 3D activation energy maps of the as-extruded ZK61 alloy at strain rates of $0.001 \mathrm{~s}^{-1}$, $0.01 \mathrm{~s}^{-1}, 0.1 \mathrm{~s}^{-1}$ and $1 \mathrm{~s}^{-1}$, where the $Q_{\text {act }}$ tends to decrease and then increase with increasing strain rate, and values of $Q_{\text {act }}$ under different temperatures and strains at lower strain rate $\left(0.001-0.01 \mathrm{~s}^{-1}\right)$ are obviously smaller than those under higher strain rate $\left(0.1-1 \mathrm{~s}^{-1}\right)$.

\subsubsection{Effect of temperature on activation energy}

The evolution of $Q_{\text {act }}$ under different deformation temperatures is shown in Fig. 18. The $Q_{\text {act }}$ initially increases and then decreases rapidly with increasing temperature, and the maximum value is prone to appear at the temperature of $623 \mathrm{~K}$. This is because the extended dislocation with large width can hardly extricate from the dislocation net due to the low stacking-fault energy of $\mathrm{Mg}$ alloys [57]. This makes the dislocation slipping and climbing limited and the occurrence of DRV difficult. Since the DRX can be induced more easily with the increase of temperature, the thermal 
energy required for overcoming energy barrier increases. Accordingly, the $Q_{\text {act }}$ tends to increase at temperatures of $523 \sim 623 \mathrm{~K}$ accompanying with inadequate dynamic restoration.

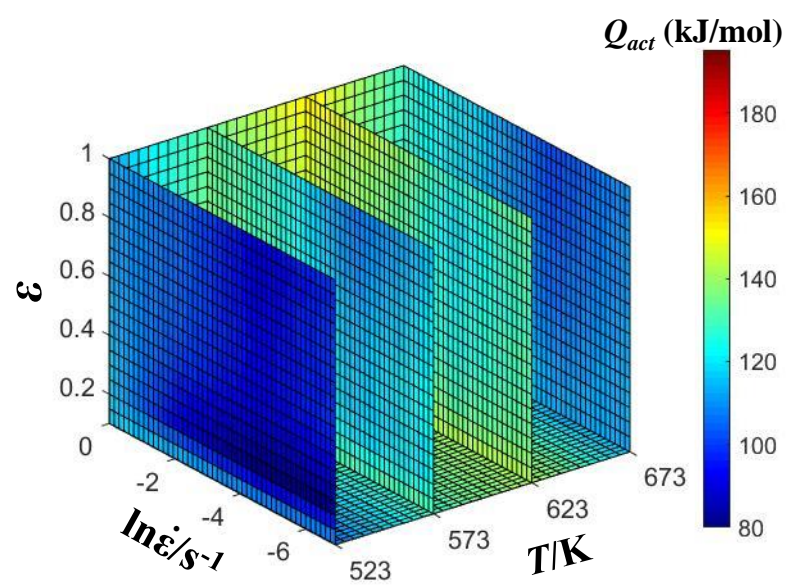

Fig. 18. 3D activation energy maps of the as-extruded ZK61 alloy at temperatures of 523K, $573 \mathrm{~K}, 623 \mathrm{~K}$ and $673 \mathrm{~K}$, where the $Q_{\text {act }}$ increases and then decrease as temperature increases. The peak area of $Q_{\text {act }}$ can be observed at temperature of $623 \mathrm{~K}$, and the sensitivity of $Q_{\text {act }}$ to temperature increases with the further increase of temperature at higher temperatures $(623 \sim 673 \mathrm{~K})$.

As is commonly recognized, the dislocation motion is a thermal activation process where the atomic activity and dislocation slipping can be promoted under high temperature. The mean speed of dislocation motion which is influenced by multiple factors can be expressed as follows [42]:

$$
\bar{v}=\beta b v \exp \left(-\frac{\Delta G\left(\sigma_{s}\right)}{k T}\right)
$$

where, $\beta$ is the dimensionless constant, $k$ is the Boltzmann constant and $k=1.3807 \times 10^{-23} \mathrm{~J} / \mathrm{K}, v$ is the attempt frequency, and the free energy of activation $\Delta \mathrm{G}\left(\sigma_{\mathrm{s}}\right)$ can be calculated by:

$$
\Delta G\left(\sigma_{s}\right)=\Delta F\left(1-\frac{\sigma_{s}}{\tau}\right)
$$

where, $\Delta F$ is the total free energy used for overcoming the obstacle without aid from external stress, $\sigma_{\mathrm{s}}$ is the yield stress and $\tau$ is the external stress forcing the dislocation through the obstacle without aid from thermal energy.

According to the Eqs. (24-25), the dislocation density can be reduced with the increase of temperature at a given strain rate. This is consistent with variations of $Q_{\text {act }}$ at temperatures of $623-673 \mathrm{~K}$ in Fig. 18. This is because the level of dynamic restoration can be improved via the increase of temperature, which is helpful to decrease the dislocation density. And thus the resistance of dislocation motion can be reduced. The decreasing trend of $Q_{\text {act }}$ exhibits with further increase of 
temperature due to the facilitated dislocation motion. Therefore, higher temperatures $(623 \sim 673 \mathrm{~K})$ are efficient to reduce the $Q_{\text {act }}$ and improve the workability.

\subsubsection{Effect of strain on activation energy}

The evolution of $Q_{\text {act }}$ under different strains is shown in Fig. 19. The $Q_{\text {act }}$ increases firstly before the strain of 0.2 and decreases rapidly with increasing strains. This is because that the energy barrier increases due to the significant $\mathrm{WH}$ at the initial stage where the dislocation density increases rapidly and dislocation pile-up tends to occur. The dynamic restoration appears and the stored energy is consumed as strain increases, which accelerated the formation of new grains. Thus, the deformation becomes easier and the $Q_{\text {act }}$ decreases quickly when the strain is higher than 0.2. The $Q_{\text {act }}$ tends to increase slightly again and the minimum value occur at strain of 0.9 . It is because a number of original boundaries are consumed by DRX, and the nucleation sites decrease and the level of dynamic restoration is thus weakened. The twins are also induced to coordinate deformation at large strains, but the original grains are segmented and refined because of the twin intersections, which can enhance the hardening behaviour. Despite of the existed DRX softening, the dislocation can still be multiplied with the increase of the energy barrier for dislocation motion due to the influence of GRS and OS. These make the $Q_{\text {act }}$ continue to slight increase after the strain of 0.9. As a consequence, a considerable decrease of $Q_{\text {act }}$ can be resulted from the increase of deformation and the lower $Q_{\text {act }}$ can be obtained at a certain level of strain.

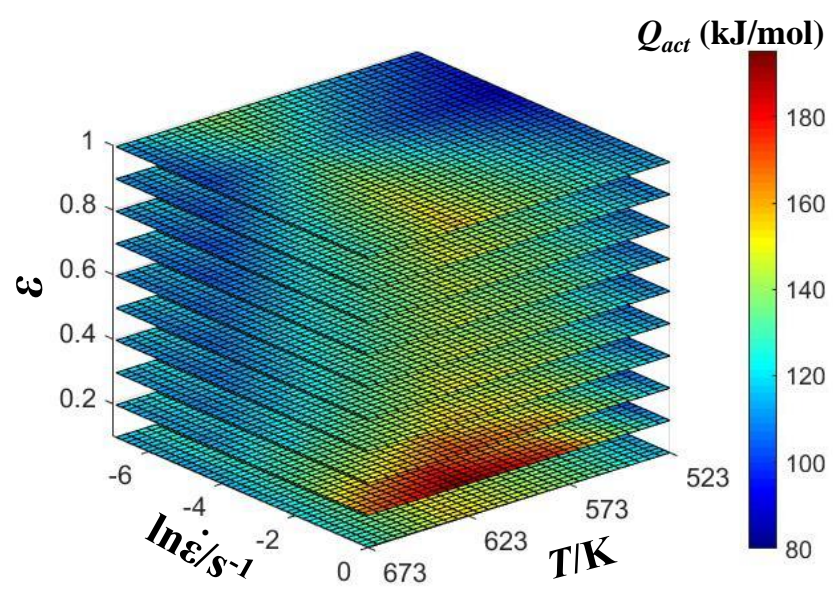

Fig. 19. 3D activation energy maps of the as-extruded ZK61 alloy at strains of 0.1-1, where the $Q_{\text {act }}$ initially increases and then decreases quickly as strain increases, while $Q_{\text {act }}$ increases slowly with the further increase of strain. The peak area of $Q_{\text {act }}$ can be observed at the strain of 0.2 , and the sensitivity of $Q_{\text {act }}$ to strain tends to increase and then decrease with the increase of strain. 


\section{Conclusions}

The isothermal compression tests of an as-extruded magnesium alloy ZK61 were carried out in the temperature range of $523 \sim 673 \mathrm{~K}$ and strain rate range of $0.001-1 \mathrm{~s}^{-1}$. The flow characteristics and workability of this alloy during hot deformation was investigated and characterized by using the improved constitutive equations and the developed activation energy maps. The main conclusions can be obtained as follows:

(1) The shapes of flow stress curves after the peak stress vary with increasing strain. These curves decrease continuously at $523 \sim 573 \mathrm{~K}$ and $0.1-1 \mathrm{~s}^{-1}$ owing to flow softening caused by incomplete DRX, while they initially decrease and gradually increase at $623 \sim 673 \mathrm{~K}$ and $0.001-0.01 \mathrm{~s}^{-1}$ due to secondary hardening resulted from fine DRX grains, intersecting twins and precipitates. The calculated strain rate sensitivity values indicate that the alloy exhibits superplasticity in the temperature range of $560 \sim 600 \mathrm{~K}$ and at strain rate of $0.001 \mathrm{~s}^{-1}$.

(2) Considering the effects of thermo-mechanical parameters on the flow behaviour, the improved Arrhenius constitutive equations were presented, which treat material parameters $A, n$ and $Q_{\text {act }}$ as functions of temperature and strain rate. The peak flow stress of this alloy can be better predicted by the improved Arrhenius constitutive equations, compared with conventional ones at temperatures between $523 \sim 673 \mathrm{~K}$ and strain rates within $0.001-1 \mathrm{~s}^{-1}$.

(3) The activation energy map at the peak strain, which describes the correlation of $Q_{\text {act }}$ values, temperature and strain rate, was constructed on the basis of the improved constitutive equations. Combining with microstructural observations, the safe region where the $Q_{\text {act }}$ varies in a quite small range of $115 \sim 124 \mathrm{~kJ} / \mathrm{mol}$ tends to occur in the low strain rate and high temperature, which is conducive to the occurrence of DRX and plastic deformation.

(4) The evolution of $Q_{\text {act }}$ values is highly sensitive to strain as well as temperature and strain rate, revealing that workability of the alloy can be changed with deformation parameters. According to the constructed 3D activation energy maps, this alloy shows lower $Q_{\text {act }}$ at the strain rates ranging from $0.001-0.01 \mathrm{~s}^{-1}$, temperatures ranging from $623 \sim 673 \mathrm{~K}$ and a certain level strain of 0.9 , which can be considered as the optimal hot processing window. 


\section{Acknowledgements}

The research reported in this paper is financially supported by National Natural Science Foundation of China (No. 51775194). One of the authors, Jinchuan Long, also would like to acknowledge financial support from the Chinese Scholarship Council (CSC) which enabled him to conduct the research at the University of Strathclyde, UK.

\section{References}

[1] Koh Y, et al. Characterization of mechanical property of magnesium AZ31 alloy sheets for warm temperature forming. Int J Mech Sci 2015;93:204-217.

[2] Proust G. Processing magnesium at room temperature. Science 2019;365:30-31.

[3] Liu C, et al. An integrated crystal plasticity-phase field model for spatially resolved twin nucleation, propagation, and growth in hexagonal materials. Int J Plast 2018;106:203-227.

[4] Tadano, Y. Formability of magnesium sheet with rolling texture. Int J Mech Sci 2016;108:72-82.

[5] Liu C, et al. On the interaction of precipitates and tensile twins in magnesium alloys. Acta Mater 2019; 178:146-162.

[6] Dong S, et al. Characteristic cyclic plastic deformation in ZK60 magnesium alloy. Int J Plast $2017 ; 91: 25-47$

[7] $\mathrm{Xu} \mathrm{ZM}$, et al. Hot Deformation Behavior and Workability of As-Cast Dilute Mg-1.2 Zn-0.2 Y Alloy. JOM 2019;71:4125-4135.

[8] Rao KP, et al. Review on Hot Working Behavior and Strength of Calcium-Containing Magnesium Alloys. Adv Eng Mater 2018;20:1701102.

[9] Bhattacharya R, Wynne BP, Rainforth WM. Flow softening behaviour during dynamic recrystallization in Mg-3Al-1Zn magnesium alloy. Scripta Mater 2012;67:277-280.

[10] He YB, et al. Modeling of strain hardening and dynamic recrystallization of ZK60 magnesium alloy during hot deformation. T Nonferr Metal Soc 2012;22:246-254.

[11] Galiyev A, Kaibyshev R, Gottstein G. Correlation of plastic deformation and dynamic recrystallization in magnesium alloy Zk60. Acta Mater 2001;49:1199-1207.

[12] Cai J., et al. Constitutive equations for elevated temperature flow stress of Ti-6Al-4V alloy considering the effect of strain. Mater Design 2011;32:1144-1151.

[13] Lin YC, Chen XM. A critical review of experimental results and constitutive descriptions for metals and alloys in hot working. Mater. Design 2011;32:1733-1759. 
[14] Lin YC, et al. Microstructural evolution and constitutive models to predict hot deformation behaviors of a nickel-based superalloy. Vacuum 2017;137:104-114.

[15] Xu Y, Hu LX, Sun Y. Hot deformation behavior and microstructure evolution of as-cast AZ91D magnesium alloy without pre-homogenization treatment. Rare Metals 2013;32: 338-346.

[16] Mei RB, et al. Simulation of the flow behavior of AZ91 magnesium alloys at high deformation temperatures using a piecewise function of constitutive equations. Mech Mater 2018;125:110-120.

[17] Wang LX, et al. Constitutive behavior and microstructure evolution of the as-extruded AE21 magnesium alloy during hot compression testing. J Alloy Compd 2015;622:121-129.

[18] Yu DH. Modeling high-temperature tensile deformation behavior of AZ31B magnesium alloy considering strain effects. Mater. Design 2013;51:323-330.

[19] Gall S, et al. Hot working behavior of AZ31 and ME21 magnesium alloys. J Mater Sci 2013;48:473-480.

[20] Malik A, et al. Constitutive analysis, twinning, recrystallization, and crack in fine-grained ZK61 Mg alloy during high strain rate compression over a wide range of temperatures. Mater Sci Eng A 2020;771.

[21] Mirzadeh H. Constitutive behaviors of magnesium and $\mathrm{Mg}-\mathrm{Zn}-\mathrm{Zr}$ alloy during hot deformation. Mater Chem Phys 2015;152:123-126.

[22] Li JQ, Liu J, Cui ZS. Characterization of hot deformation behavior of extruded ZK60 magnesium alloy using 3D processing maps. Mater Design 2014;56:889-897.

[23] Xia X, et al. Hot deformation behavior of extruded Mg-Zn-Y-Zr alloy. J Alloy Compd 2015;644:308-316.

[24] Sani SA, et al. Modeling of hot deformation behavior and prediction of flow stress in a magnesium alloy using constitutive equation and artificial neural network (ANN) model. J. Magnes. Alloys 2018;6:134-144.

[25] Rezaee M, et al. Flow Characterization of a Duplex near alpha Ti6242 Alloy through Interrelation of Microstructural Evolution, 3D Activation Energy Map, and Processing Map. Adv Eng Mater 2016;18:1075-1085.

[26] Wang S, et al. Characterization of hot workability in AA 7050 aluminum alloy using activation energy and 3-D processing map. J Mater Process Technol 2015;225, 110-121.

[27] Su ZX, et al. Physical-based constitutive model considering the microstructure evolution during hot working of AZ80 magnesium alloy. Adv Manuf 2019;7:30-41.

[28] Schindler I, et al. Activation Energy in Hot Forming and Recrystallization Models for Magnesium Alloy AZ31. J Mater Eng Perform 2013;22:890-897.

[29] Arun MS, Chakkingal U. A constitutive model to describe high temperature flow behavior of AZ31B magnesium alloy processed by equal-channel angular pressing. Mater Sci Eng A, 
2019;754:659-673.

[30] Gui ZZ, Kang ZX, Li YY. Evolution of the microstructure and fracture characteristics of a $\mathrm{Mg}-\mathrm{Nd}-\mathrm{Zn}-\mathrm{Zr}-\mathrm{Mn}$ alloy through heat treatment and extrusion. $\mathrm{J}$ Alloys Compd 2018;765:470-479

[31] Shi CJ, Lai J, Chen XG. Microstructural Evolution and Dynamic Softening Mechanisms of Al-Zn-Mg-Cu Alloy during Hot Compressive Deformation. Materials 2014;7:244-264.

[32] Lapovok R, et al. Extraordinary superplastic ductility of magnesium alloy ZK60. J Mater Res 2005(20):1375-1378

[33] Xiao, Gf, et al. Research on precise control of microstructure and mechanical properties of Ni-based superalloy cylindrical parts during hot backward flow spinning. J Manuf Process 2018;34:140-147.

[34] Kim, B, et al. High-strain-rate superplasticity of fine-grained $\mathrm{Mg}-6 \mathrm{Zn}-0.5 \mathrm{Zr}$ alloy subjected to low-temperature indirect extrusion. Scr Mater 2017(141):138-142.

[35] Peng WW, et al. Characterization of high-temperature deformation behaviour of as-cast Ti60 titanium alloy using processing map. Mater Sci Eng A 2013(571):116-122.

[36] Shang XQ, Cui ZS, Fu MW. A ductile fracture model considering stress state and Zener-Hollomon parameter for hot deformation of metallic materials. Int $\mathrm{J}$ Mech Sci 2018;144: 800-812.

[37] Sun Y, et al. Characterization of hot processing parameters of powder metallurgy TiAl-based alloy based on the activation energy map and processing map. Mater Design 2015;86:922-932.

[38] Barezban $\mathrm{MH}$, et al. Constitutive analysis of wrought $\mathrm{Mg}-\mathrm{Gd}$ magnesium alloys during hot compression at elevated temperatures. J Alloy Compd 2019;791:1200-1206.

[39] Mirzadeh $\mathrm{H}$, et al. Constitutive relationships for hot deformation of austenite. Acta Mater 2011;59:6441-6448.

[ 40 ] Zhao DQ, et al. Constitutive modeling for dynamic recrystallization kinetics of Mg-4Zn-2Al-2Sn alloy. T Nonferr Metal Soc 2018;28:340-347.

[41] Xie QJ, et al. Crystal plasticity-based impact dynamic constitutive model of magnesium alloy. Int J Mech Sci 2016;119:107-113.

[42] Mirzadeh $\mathrm{H}$, et al. Rate controlling mechanisms during hot deformation of $\mathrm{Mg}-3 \mathrm{Gd}-1 \mathrm{Zn}$ magnesium alloy: dislocation glide and climb, dynamic recrystallization, and mechanical twinning. Mater Des 2015;68:228-231.

[43] Mirzadeh H. Constitutive analysis of Mg-Al-Zn magnesium alloys during hot deformation. Mech Mater 2014;77:80-85.

[44] Mirzadeh H. Quantification of the strengthening effect of rare earth elements during hot deformation of Mg-Gd-Y-Zr magnesium alloy. J Mater Res Technol 2016;5:1-4. 
[45] Caillard D, Martin JL. Thermally activated mechanisms in crystal plasticity. MRS Bull 2005;30:319.

[46] Shi CJ, et al. Evolution of activation energy during hot deformation of AA7150 aluminum alloy. Mater Sci Eng A 2013;571:83-91.

[47] Cai ZW, Chen FX, Guo JQ. Constitutive model for elevated temperature flow stress of AZ41M magnesium alloy considering the compensation of strain. J Alloy Compd 2015;648; 215-222.

[48] McQueen HJ. Development of dynamic recrystallization theory. Mater Sci Eng A 2004;387:203-208.

[49] Son KT, et al. Evaluation of hot deformation characteristics in modified AA5052 using processing map and activation energy map under deformation heating. J Alloy Compd 2018;740:96-108.

[50] Zhang JQ, et al. Hot deformation behavior of Ti-15-3 titanium alloy: a study using processing maps, activation energy map, and Zener-Hollomon parameter map. J Mater Sci 2012;47:4000-4011.

[51] Jenab A, Taheri AK. Experimental investigation of the hot deformation behaviour of AA7075: Development and comparison of flow localization parameter and dynamic material model processing maps. Int J Mech Sci 2014;78:97-105.

[52] Zhan MY, et al. Flow stress behavior of porous FVS0812 aluminum alloy during hot-compression. Mech Res Commun 2006;33:508-514.

[53] Mirzadeh H. A simplified approach for developing constitutive equations for modeling and prediction of hot deformation flow stress. Metal Mater Trans A 2015;46:4027-4037.

[54] Xia QX, et al. Constitutive Model of Extruded ZK61 Magnesium Alloy at High Temperature Considering Compensation of Strain. In: 2019 16th National Conference on Technology of Plasticity; October 2019. p. 299-302. (In Chinese)

[55] Zhang MJ, et al. Characterization of hot deformation behavior of a P/M nickel-base superalloy using processing map and activation energy. Mater Sci Eng A 2010;527:6771-6779.

[56] Humphreys FJ, Hatherly M. Recrystallization and related annealing phenomena. Elsevier 2012.

[57] Myshlyaev MM, et al. Twinning, dynamic recovery and recrystallization in hot worked Mg-Al-Zn alloy. Mater Sci Eng A 2002;337:121-133. 